\title{
Levels of Malondialdehyde and Superoxide Dismutase in Subclinical Hyperthyroidism
}

\author{
Ali Cetinkaya, ${ }^{1}$ Ergul Belge Kurutas, ${ }^{2}$ Mehmet Akif Buyukbese, ${ }^{1}$ Bulent Kantarceken, ${ }^{1}$ and Ertan Bulbuloglu ${ }^{3}$ \\ ${ }^{1}$ Department of Internal Medicine, Medical Faculty, Sutcu Imam University, Kahramanmaras-46060, Turkey \\ ${ }^{2}$ Department of Biochemistry, Medical Faculty, Sutcu Imam University, Kahramanmaras-46060, Turkey \\ ${ }^{3}$ Department of General Surgery, Medical Faculty, Sutcu Imam University, Kahramanmaras-46060, Turkey
}

Received 9 November 2004; accepted 25 November 2004

\begin{abstract}
We aimed to determine whether patients with subclinical hyperthyroidism ( $\mathrm{SH}$ ) are subject to oxidative stress. Twenty-two women and 8 men having endogenous subclinical hyperthyroidism for a duration of at least 6 months, and 21 women and 9 men healthy controls were included in this study. We measured the level of plasma malondialdehyde, as one of the lipid peroxidation markers, and the activity of erythrocyte superoxide dismutase, which is an antioxidant enzyme. The activity of erythrocyte superoxide dismutase and plasma malondialdehyde levels were found to be significantly higher in subjects with subclinical hyperthyroidism than the control group $(P<.01)$. The results of this study suggest that oxidative stress and antioxidative response could be increased in patients having subclinical hyperthyroidism.
\end{abstract}

\section{INTRODUCTION}

Aerobic organisms possess antioxidant defense systems that deal with reactive oxygen species (ROS) as a result of aerobic respiration substrate oxidation. ROS, including hydroxyl radicals $\left(\mathrm{OH}^{*}\right)$, superoxide anions $\left(\mathrm{O}_{2}{ }^{-}\right)$, and hydrogen peroxide $\left(\mathrm{H}_{2} \mathrm{O}_{2}\right)$, are generated in response to external and internal stimuli. Low levels of ROS are necessary for several biological processes including intracellular differentiation and cell progression or arrest of apoptosis growth, immunity, and defense against microorganisms. In contrast, high doses and/or inadequate removal of ROS result in oxidative stress, which may cause damage to biological macromolecules [1].

Lipid peroxidation is a normal phenomenon that occurs continuously at low levels in every individual. Those peroxidation reactions are toxic to cells and cell membranes; however, they are normally controlled by countervailing biological mechanisms. Severe oxidative stress produces ROS and induces uncontrolled lipid peroxidation. Following lipid peroxidation aldehydic products, such as free fatty acids, malondialdehyde (MDA), occur and those products are referred to as thiobarbituric acidreacting substances. Since the cell membranes consist primarily of lipids, uncontrolled lipid peroxidation can cause

Correspondence and reprint requests to Ali Cetinkaya, Department of Internal Medicine, Medical Faculty, Sutcu Imam University, Kahramanmaras-46060, Turkey; alicetinkaya@ksu. edu.tr cell injury and death via DNA damage and directly inhibiting proteins, such as $\mathrm{Na}+/ \mathrm{K}$-ATPases and glutamate transporters [2]. The protecting feature of SOD, one of the antioxidant enzymes, against oxidative stress bears an essential role for life [3].

Subclinical hyperthyroidism (SH) is characterised by reduced serum thyrotrophin (TSH) levels despite free thyroxine $\left(\mathrm{FT}_{4}\right)$ and free triiodothyronine $\left(\mathrm{FT}_{3}\right)$ estimates within the reference range, in subjects with no obvious symptoms of hyperthyroidism. It has been reported that hyperthyroidism leads to a hypermetabolic state and accelerates free radical production to induce changes in antioxidant enzyme activities. However, to our knowledge, there is no study in the literature about the role of oxidative stress in SH. For that reason, we aimed to investigate if there is any relation between the increase in oxidative stress and $\mathrm{SH}$.

\section{MATERIALS AND METHODS}

Twenty-two women and 8 men having endogenous $\mathrm{SH}$ for a duration of at least 6 months, with an age range of 26-68 years (mean: $42.16 \pm 9.69$ years), and 21 women and 9 men healthy controls having an age range of 29-65 years (mean: $40.96 \pm 7.69$ years) were included in this study. All subclinical hyperthyroid patients were presented with multinodular goitre as evaluated by scintigraphy and ultrasound. None of the patients or control subjects had diabetes mellitus, pituitary and other acute or chronic systemic diseases. Also, none of the patients were taking L-tiroxine or antithyroid drugs for 
TABLE 1. Laboratory findings in patients with subclinical hyperthyroidism and control group. NS (not significant); Hb, (haemoglobin).

\begin{tabular}{lccc}
\hline Variable & Patients with SH & Control group & $P$ \\
\hline $\mathrm{TT}_{3}(\mathrm{IU} / \mathrm{mL})$ & $1.44 \pm 0.38$ & $1.37 \pm 0.24$ & $\mathrm{NS}$ \\
$\mathrm{TT}_{4}(\mathrm{ng} / \mathrm{mL})$ & $9.06 \pm 1.42$ & $9.07 \pm 1.20$ & $\mathrm{NS}$ \\
$\mathrm{FT}_{3}(\mathrm{pg} / \mathrm{dL})$ & $4.28 \pm 0.97$ & $4.13 \pm 0.67$ & $\mathrm{NS}$ \\
$\mathrm{FT}_{4}(\mathrm{ng} / \mathrm{dL})$ & $0.71 \pm 0.11$ & $0.73 \pm 0.17$ & $\mathrm{NS}$ \\
$\mathrm{TSH}(\mathrm{mIU} / \mathrm{mL})$ & $0.09 \pm 0.08$ & $1.61 \pm 0.65$ & $<.01$ \\
$\mathrm{MDA}(\mathrm{nmol} / \mathrm{L})$ & $3.34 \pm 0.50$ & $2.12 \pm 0.26$ & $<.01$ \\
$\mathrm{SOD}(\mathrm{U} / \mathrm{gHb})$ & $3042.33 \pm 908.03$ & $2024.70 \pm 501.11$ & $<.01$ \\
\hline
\end{tabular}

hyperthyroidism. Written consent was obtained from all patients after giving them information about the study.

Free $\mathrm{T}_{3}\left(\mathrm{FT}_{3}\right)$, total $\mathrm{T}_{3}\left(\mathrm{TT}_{3}\right)$, free $\mathrm{T}_{4}\left(\mathrm{FT}_{4}\right)$, total $\mathrm{T}_{4}\left(\mathrm{TT}_{4}\right)$, and ultrasensitive TSH were measured with Immulite 2000 by the immunoassay method. Erythrocyte SOD activity was measured according to the method described by Fridovich [4]. SOD activity was expressed as $\mathrm{U} / \mathrm{gHb}$. Plasma MDA was measured according to procedure of Ohkawa et al [5]. MDA level was expressed as $\mathrm{nmol} / \mathrm{mL}$.

Statistical analysis was carried out with the SPSS-X (Release 4.1) programme. All data were expressed as the mean \pm SD. The control and patient groups for each parameter were compared with Student $t$ test. Differences were considered significant when $P<.05$.

\section{RESULTS}

The average activity of SOD in patients with $\mathrm{SH}$ was $3042.33 \pm 908.03$ while it was $2024.70 \pm 501.11$ in the control group $(P<.01)$. The level of MDA in patients with SH was $3.34 \pm 0.50$ while it was $2.12 \pm 0.26$ in the control group $(P<.01)$. These data and thyroid hormone levels are presented in Table 1.

\section{DISCUSSION}

Recently, increasing experimental and clinical studies have shown that free radicals play a role in the etiology of many illnesses. Similarly the importance of oxidative process in the beginning of tissue damage due to hyperthyroidism has been demonstrated. It has been demonstrated that increased production of free oxygen radicals is especially seen in microsomal fraction of the liver in experimentally hyperthyroid rats. It has been thought that the increase in lipid peroxide levels is originated from the impairment of the polyunsaturated fatty acids due to free radical oxidation.

In the recent studies systemic effects of $\mathrm{SH}$ have been shown to be as in clinical hyperthyroidism. Some studies have put forward that SH has effects such as increased cardiac disorders, decrease in the quality of life, and causing mortality. Also, there are studies showing that $\mathrm{SH}$ increases the risk of bone loss, dementia, and Alzheimer's disease. Although many experimental and clinical investigations have been conducted about oxidative stress and antioxidant capacity in hyperthyroidism, we were not able to find any relevant data in electronic databases about $\mathrm{SH}$.

There is a controversy whether hyperthyroidism is associated with an increase or decrease in the activities of antioxidant enzymes. It is reported that SOD activity was increased in the cardiac muscle and liver in hyperthyroid rats [6]. Also, the increase of SOD have been shown in the blood of patients with hyperthyroidism. On the contrary, some investigators found decreased SOD activity in the blood samples of patients with hyperthyroidism [7].

We speculate that $\mathrm{SH}$ gives rise to oxidative stress, then high levels of free radicals inside the cells increase the MDA levels and the organism defends itself against the effects of oxidative stress by increasing SOD activity as a protection mechanism. In our study we measured more statistically significant SOD activity in the subclinical hyperthyroid group than in the control group. This suggests that antioxidant defence of the patients increases possibly due to a compensatory response to increased peroxidation in the body and thereby protects the cells against oxidative damage. That finding may be considered to be indirect evidence to support the protective role of SOD against peroxidation.

In conclusion, the oxidative stress associated with SH may play an important role in the systemic effects and progression to hyperthyroidism. Further largepopulation-based detailed studies to understand oxidative stress and antioxidant capacity in $\mathrm{SH}$ are needed to determine these interactions.

\section{REFERENCES}

[1] Georgeson GD, Szony BJ, Streitman K, et al. Antioxidant enzyme activities are decreased in preterm infants and in neonates born via caesarean section. Eur J Obstet Gynecol Reprod Biol. 2002;103(2):136-139.

[2] Nakai A, Oya A, Kobe H, et al. Changes in maternal lipid peroxidation levels and antioxidant enzymatic activities before and after delivery. J Nippon Med Sch. 2000;67(6):434-439.

[3] Loeper J, Goy J, Rozensztajn L, Bedu O, Moisson P. Lipid peroxidation and protective enzymes during 
myocardial infarction. Clin Chim Acta. 1991;196(23):119-125.

[4] Fridovich I. Superoxide radical: an endogenous toxicant. Annu Rev Pharmacol Toxicol. 1983;23:239-257.

[5] Ohkawa H, Ohishi N, Yagi K. Assay for lipid peroxides in animal tissues by thiobarbituric acid reaction. Anal Biochem. 1979;95(2):351-358.

[6] Asayama K, Dobashi K, Hayashibe H, Kato K. Effects of beta-adrenergic blockers with different ancillary properties on lipid peroxidation in hyperthyroid rat cardiac muscle. Endocrinol Jpn. 1989;36(5):687-694.

[7] Fernandez V, Llesuy S, Solari L, Kipreos K, Videla LA, Boveris A. Chemiluminescent and respiratory responses related to thyroid hormone-induced liver oxidative stress. Free Radic Res Commun. 1988;5(2):7784. 


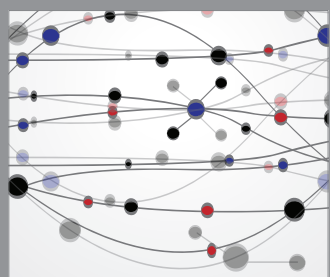

The Scientific World Journal
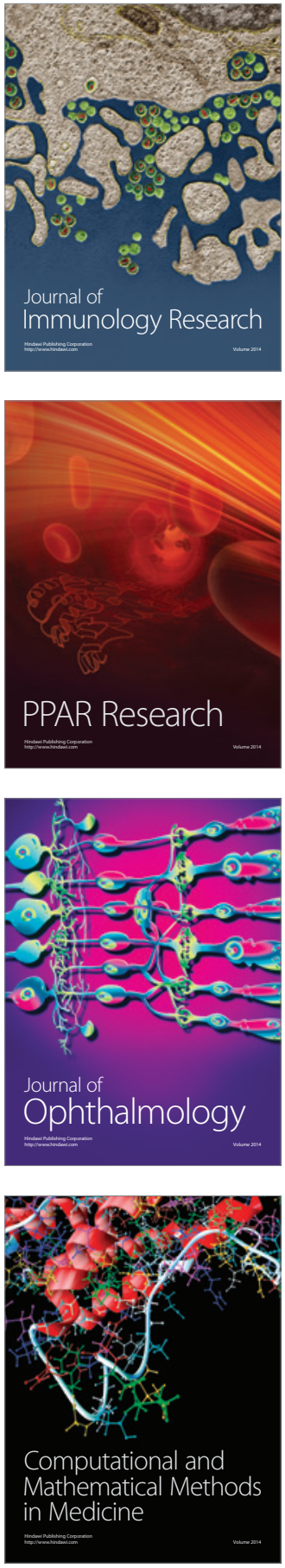

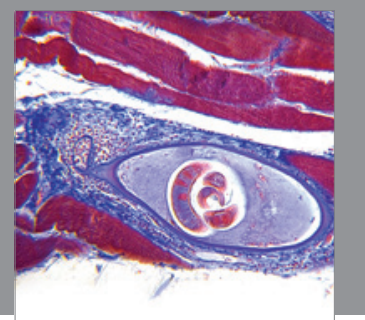

Gastroenterology

Research and Practice
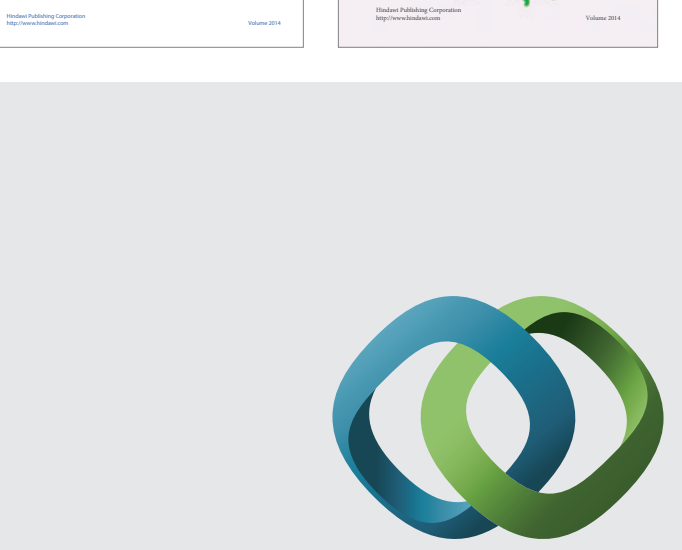

\section{Hindawi}

Submit your manuscripts at

http://www.hindawi.com
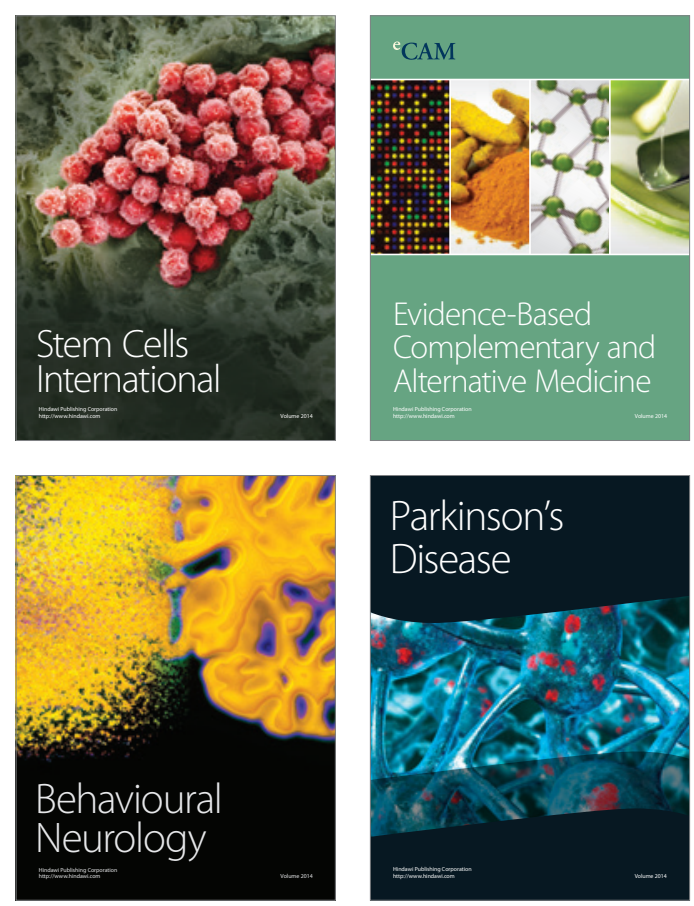

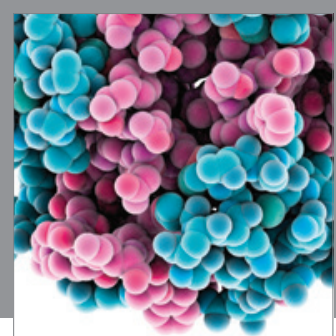

Journal of
Diabetes Research

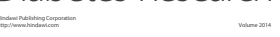

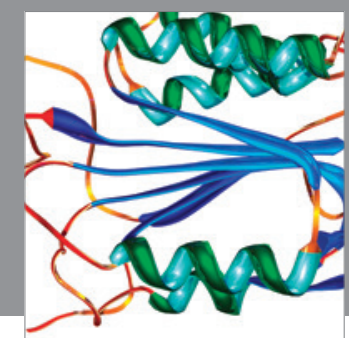

Disease Markers
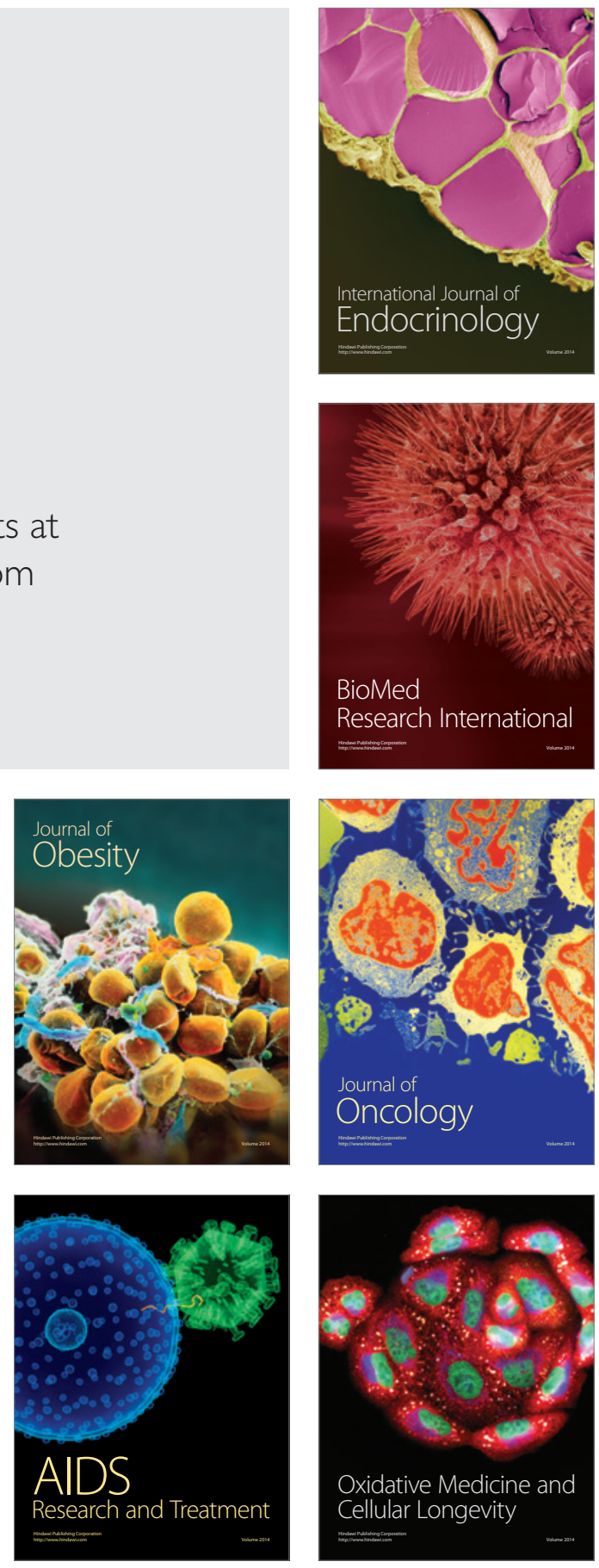